\title{
Maternal Vitamin D in the Late First and Second Trimester is Beneficial for Healthy Development of Fetal Head Circumference
}

Noboru Hasegawa ${ }^{*}$, Emiko Manabe ${ }^{1}$, Mie Izumi ${ }^{1}$ and Miyako Mochizuki ${ }^{2}$

${ }^{1}$ Doshisha Women's College of Liberal Arts, Kodo, Kyotanabe, Kyoto 610-0395, Japan

${ }^{2}$ Kyoto Bunkyo Junior College, 80 Senzoku, Makishima-cho, Uji, Kyoto 611-0041, Japan

\begin{abstract}
Background: We previously showed that vitamin D supplementation might ameliorate typical clinical symptoms in children with autism spectrum disorder. In this study we examined the effects of maternal vitamin D status during pregnancy on the development of the fetus.
\end{abstract}

Methods: Seventy-eight healthy Japanese women with uncomplicated pregnancies were enrolled in the study. Urine 25-hydroxy vitamin D (25OHD) and creatinine were measured. 25OHD concentrations were normalized for creatinine (ng/mg creatinine). Newborn anthropometry (height $(\mathrm{cm})$, head circumference $(\mathrm{cm})$, chest circumference $(\mathrm{cm})$ and birth weight $(\mathrm{kg})$ ) of babies delivered naturally were measured and the relationship with the urinary vitamin $\mathrm{D}$ concentration of the mother at less than 90 days (third trimester) to delivery and more than 90 days to delivery (late first to second trimester) was examined. PC12 cells with various neurobiological processes were cultured and differentiation induced by $25 \mathrm{OHD}$ enhanced nerve growth factor was assessed.

Results: Maternal and newborn characteristics were not significantly different between the late first and third trimesters. The associations between newborn length, chest circumference, birth weight and the urinary 25OHD concentration of mother in the late first and second trimester and the third trimester were not significant. As lightly positive association between urinary $25 \mathrm{OHD}$ and head circumference was observed in the late first and second trimester $(r=0.309)$, but not in the third trimester. Six nmol/L of 25OHD $(=1 / 5$ of serum level) enhanced nerve growth factor induced differentiation in PC12 cells.

Conclusion: These findings show that vitamin D supplementation in the late first and second trimester beneficial for the healthy development of the fetal head circumference and neural system.

\section{Introduction}

Vitamin D is a secosteroid associated with peripheral calcium homeostasis and nervous system function [1]. Significant changes in maternal vitamin $\mathrm{D}$ and calcium metabolism occur during pregnancy to provide calcium for fetal bone mineral accretion [2]. It is important that $25 \mathrm{OHD}$ readily crosses the placental tissue to the fetus $[3,4]$. Low 25OHD levels in the maternal and cord blood have been found to be significantly associated with decreased birth weight of infants [5]. Vitamin D deficiency is common in preterm infants [6] and vitamin $\mathrm{D}$ supplementation in women at high risk of vitamin $\mathrm{D}$ deficiency leads to improved neonatal handling of $\mathrm{Ca}$ [2]. Many studies have shown that maternal vitamin D level might affect fetal growth.

Autism spectrum disorders are developmental disorders associated with a high individual and social burden, but their aetiology is poorly understood. We previously reported that vitamin D supplementation for 9 months might ameliorate typical clinical symptoms in children with autism spectrum disorder [7]. Vitamin D may have an important role in the development of the brain.

In comparison with serum $25 \mathrm{OHD}$ concentration in non-pregnant women or women with uncomplicated pregnancies, half of urinary 25OHD was excreted in uncomplicated pregnant women at 15 weeks' gestation [8]. Given this, serum vitamin D state was quantified from maternal urinary vitamin $\mathrm{D}$.

PC12 cells represent a useful in vitro model of neuronal differentiation with various neurobiological properties [9]. Exposure of nerve growth factor (NGF) cause PC12 cells to differentiate into sympathetic neuron-like cells that exhibit increased neurite outgrowth

\section{Subjects and Setting}

and synapses. However, to our knowledge there has been no study analyzing the effects of vitamin D on nerve growth in vitro. Another aim of the present study was therefore to identifywhether25OHD is associated with NGF-induced nerve growth.

\section{Materials and Methods}

Prior to this study, approval was obtained from the ethics committee of Doshisha Women's College of Liberal Arts (project registration number in 2018: 2018-26). We enrolled 78 pregnant women with planned deliveries from March to August in 2019. Maternal urine samples were obtained and body weight, height, age and gravidity in maternal and child health screening in the clinic between 11th February 2019 and 15th March 2019 were recorded. Urine specimens were classified into two groups in consideration of the number of days from the urine collection day to the delivery day, and stored at $-80^{\circ} \mathrm{C}$ before analysis. One group was more than 90 days to delivery (the late first and second trimester) and the other was within 90 days to delivery (the third trimester).

"Corresponding Author: Prof. Noboru Hasegawa, Doshisha Women's College of Liberal Arts, Kodo, Kyotanabe, Kyoto 610-0395, Japan, Tel: +81-774-65-8855, Fax: +81-774-65-8820; E-mail: nhasegaw@dwc.doshisha.ac.jp

Citation: Hasegawa N, Manabe E, Izumi M, Mochizuki M (2020) Maternal Vitamin $D$ in the Late First and Second Trimester is Beneficial for Healthy Development of Fetal Head Circumference. Int J Nurs Clin Pract 7: 330. doi: https://doi. org/10.15344/2394-4978/2020/330

Copyright: (C) 2020 Hasegawa et al. This is an open-access article distributed under the terms of the Creative Commons Attribution License, which permits unrestricted use, distribution, and reproduction in any medium, provided the original author and source are credited. 
Citation: Hasegawa N, Manabe E, Izumi M, Mochizuki M (2020) Maternal Vitamin D in the Late First and Second Trimester is Beneficial for Healthy Development of Fetal Head Circumference. Int J Nurs Clin Pract 7: 330. doi: https://doi.org/10.15344/2394-4978/2020/330

Page of

\section{Serum 25OHD and creatinine}

Urinary 25OHD and creatinine were analyzed using a commercially available ELISA kit (Immundiagnostik AG, Germany) and colorimetric reaction kit using Jaffe reagent (QuantiChrom TM, CA, USA), respectively. The $25 \mathrm{OHD}$ concentrations were normalized for urinary creatinine (ng/mg creatinine).

\section{Newborn anthropometry}

Newborn anthropometry (height $(\mathrm{cm})$, head circumference $(\mathrm{cm})$, chest circumference $(\mathrm{cm})$ and birth weight $(\mathrm{kg})$ ) of babies delivered naturally were measured by skilled midwives.

\section{Cell culture and assay}

PC12 cells obtained from the Riken Cell Bank (Ibaraki, Japan) were maintained in DMEM supplemented with $10 \%$ fetal bovine and horse serum (Gibco, Life Technologies) and $1 \%$ penicillin-streptomycin (Sigma). The cells were then incubated at $37^{\circ} \mathrm{C}$ in an atmosphere of $5 \%$ CO2/95\% air. PC12 cells were seeded at a density of $1.5 \times 10^{5}$ cells [9]. Following $24 \mathrm{~h}$ of incubation, PC12 cells were treated with 0 $\mathrm{ng} / \mathrm{mL}$ NGF with or without $6 \mathrm{nmol} / \mathrm{L}$ of 25OHD. The ACE activity was measured for an index of the differentiation of the PC12 cells and expressed as absorbance mIU of $\mathrm{mg}$ protein. AchE activity and protein were analyzed using a commercially available kit (Amplite ${ }^{\mathrm{TM}}$ Colorimetric kit, AAT Bioquest, USA) and Pierce ${ }^{\mathrm{TM}}$ BCA protein assay kit (Thermofisher Scientific, USA), respectively.

\section{Statistical analysis}

The differences between urinary 25OHD and newborn anthropometry were evaluated using the t-test. AChE activity was expressed as mean $\pm \mathrm{SD}$ and evaluated using the t-test. A p-value of $<0.05$ was considered to be statistically significant. Analyses were carried out using SPSS 21 for Windows (IBM, Japan).

\section{Results and Discussion}

\section{Study subjects}

The characteristics of the study subjects are shown in Table 1. There were no significant differences in delivery characteristics between the two groups classified by the times of urine specimen collection. The height and the weight at the time of the birth were a little bigger than the mean values shown by the Ministry of Health, Labor and Welfare. These data showed that the deliveries in this study were typical Japanese deliveries.

\section{Newborn anthropometry outcomes and urinary 25OHD concentration in pregnancy}

The associations between newborn length, chest circumference and birth weight and the urinary 25OHD concentration of mothers in the late first and second trimester and the third trimester were not significant. A slightly positive association between urinary $25 \mathrm{OHD}$ and birth head circumference was observed in the late first and second trimester $(\mathrm{r}=0.358)$, but not in the third trimester (Figure 1).

The vitamin D receptor is found in multiple brain regions of the neonatal central nervous system [10,11]. Maternal vitamin D supplementation from the 2 nd half of pregnancy until birth does not influence newborn growth [12]. Our study showed a slightly positive association between birth head circumference and urinary 25OHD concentration for the late first and second trimester. These results suggest that vitamin D levels in early pregnancy (1st trimester) are associated with newborn head size.

\section{Enhancement of NGF-induced neuronal differentiation in PC12 cells by $25 \mathrm{OHD}$}

Six nmol/L of 25 OHD (=1/5 of serum level) enhanced nerve growth factor induced differentiation in PC12 cells (Figure 2).

Vitamin D plays a role in brain developmental mechanisms [13]. Lower maternal serum $25 \mathrm{OHD}$ in the first trimester is associated with a higher autism risk [14]. These results suggest that preventing vitamin D deficiency in early pregnancy is essential to decrease the risk of autism. Vitamin D deficiency is highly prevalent in the winter months, seen in $64 \%$ of pregnant women [15]. Instruction with advice on how to supplement vitamin $\mathrm{D}$ by sunbathing and vitamin $\mathrm{D}$-rich food is necessary.

This is a preliminary study with a very small number of subjects. Further study with larger numbers of subjects is warranted, and could

\begin{tabular}{|l|c|c|}
\hline \multirow{2}{*}{ Time of urine specimen collection } & \multicolumn{2}{|l|}{ Late firstand second Third trimester } \\
\cline { 2 - 3 } & trimester $\mathrm{n}=31$ & $\mathrm{p}$-Value $\mathrm{n}=48$ \\
\hline Mother & & \\
\hline Body height $(\mathrm{cm})$ & $160.2 \pm 5.3$ & $158.0 \pm 5.00 .07$ \\
\hline Body weight $(\mathrm{Kg})$ & $57.7 \pm 6.0$ & $59.5 \pm 6.40 .22$ \\
\hline Age $(\mathrm{y})$ & $30.2 \pm 4.0$ & $31.4 \pm 4.50 .26$ \\
\hline Gravidity & $1.9 \pm 0.7$ & $1.7 \pm 0.80 .36$ \\
\hline Newborn & & $3063.5 \pm 364.70 .13$ \\
\hline Birth weight $($ Kg) & $3193.4 \pm 327.7$ & $48.4 \pm 1.70 .09$ \\
\hline Length (cm) & $49.0 \pm 1.6$ & $31.6 \pm 1.40 .16$ \\
\hline Head circumference $(\mathrm{cm})$ & $32.1 \pm 1.6$ & $33.1 \pm 1.20 .39$ \\
\hline Chest circumference $(\mathrm{cm})$ & $33.4 \pm 1.2$ & $38.9 \pm 1.30 .22$ \\
\hline Gestational age (week) & $39.4 \pm 0.8$ & \\
\hline Female infant $(\%)$ & 45.241 .7 & \\
\hline $\begin{array}{l}\text { Table } 1: \text { Characteristics of maternal and newborn subjects (mean } \pm \text { SD). } \\
\text { Number of pregnancies including current pregnancy. }\end{array}$ \\
\hline
\end{tabular}


Citation: Hasegawa N, Manabe E, Izumi M, Mochizuki M (2020) Maternal Vitamin D in the Late First and Second Trimester is Beneficial for Healthy Development of Fetal Head Circumference. Int J Nurs Clin Pract 7: 330. doi: https://doi.org/10.15344/2394-4978/2020/330
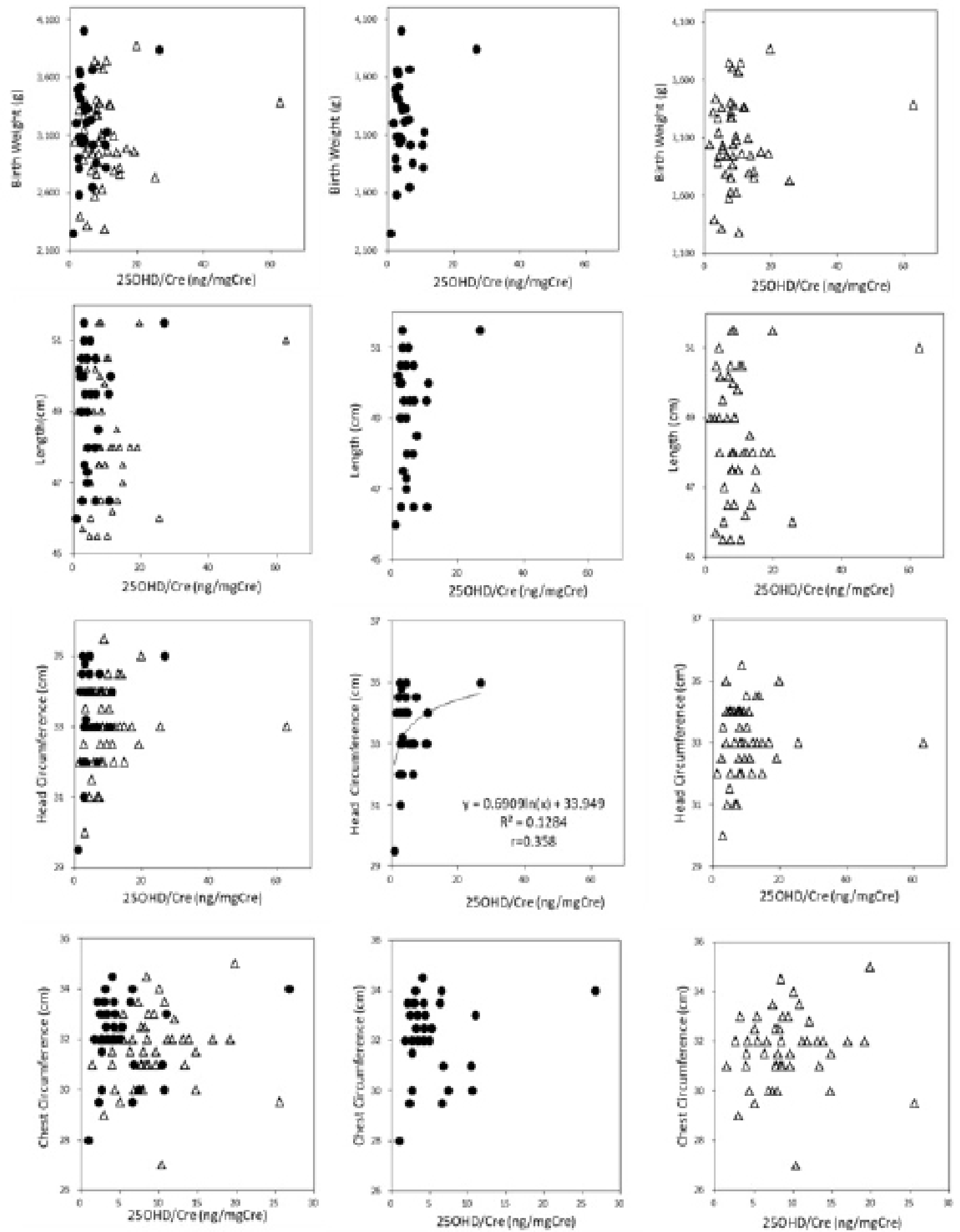

Figure1: Relationship between urinary $25 \mathrm{OHD}$ and newborn anthropometric outcome.

O: the late first and second trimester, $\triangle$ : the third trimester 
Citation: Hasegawa N, Manabe E, Izumi M, Mochizuki M (2020) Maternal Vitamin D in the Late First and Second Trimester is Beneficial for Healthy Development of Fetal Head Circumference. Int J Nurs Clin Pract 7: 330. doi: https://doi.org/10.15344/2394-4978/2020/330

Page of

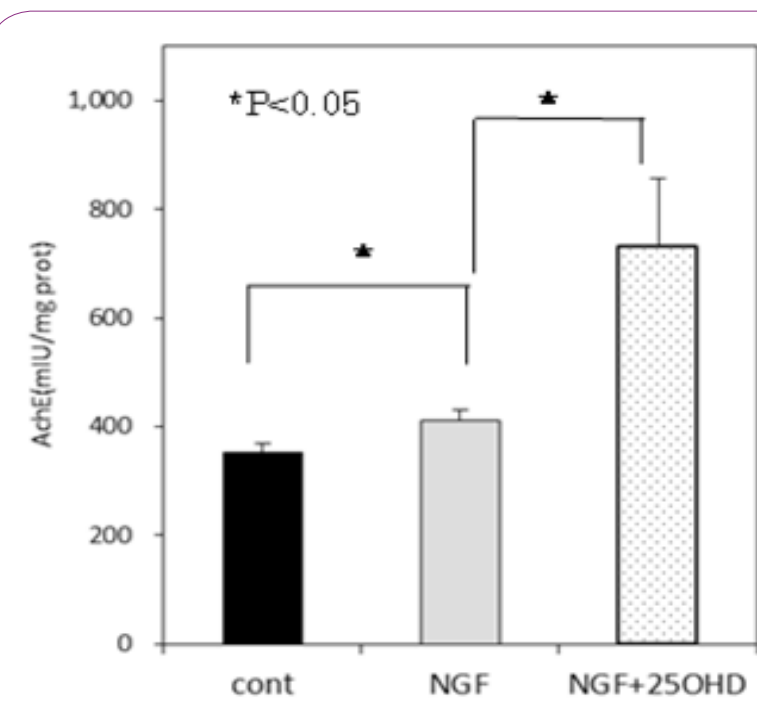

Figure 2: Nerve growth factor-induced AChE activity in PC12 cells.

reveal optimal 25 OHD levels for preventing vitamin D deficiency in the late first trimester.

\section{Conclusion}

These findings show that advice on vitamin $\mathrm{D}$ supplementation in the late first and second trimester is beneficial for the healthy development of the fetal head circumference and neural system.

\section{Competing Interest}

The authors declare that they have no competing interests.

\section{Author's Contributions}

Dr. Hasegawa was responsible for the study conception, design, analysis, interpretation of data, and drafting of the manuscript.

Dr. Manabe was responsible for the data acquisition and proof reading of the manuscript.

Dr. Izumi was responsible for the data acquisition and proof reading of the manuscript.

Ms.Mochizuki was responsible for proof reading of the manuscript, and participated in the data analysis.

\section{Acknowledgements}

The authors acknowledge Dr.Seiji Fujita of Fujita Ladies Clinic (Kyoto, Japan) for his kind help.

\section{References}

1. DeLuca GC, Kimball SM, Kolasinski J, Ramagopalan SV, Ebers GC, et al (2013) Review: the role of vitamin D in nervous system health and disease. Neuropathol Appl Neurobiol 39: 458-484.

2. Specker B (2004) Vitamin D requirements during pregnancy. Am J Clin Nutr 80: 1740 S- 1747.

3. Shin JS, Choi MY, Longtine MS, Nelson DM (2010) Vitamin D effects on pregnancy and the placenta. Placenta 31: 1027-1034.

4. Liu NQ, Hewison M (2012) Vitamin D, the placenta and pregnancy. Arch Biochem Biophys 523: 37-47.
5. Chun SK, Shin S, Kim MY, Joung H, Chung J, et al. (2017) Effects of maternal genetic polymorphisms in vitamin D-binding protein and serum 25-hydroxyvitamin D concentration on infant birth weight. Nutrition 35: 36 42.

6. Charlton JR, Harer MW, Swan C, Nielsen R (2019) Immature megalin expression in the preterm neonatal kidney is associated with urinary loss of vitamin carrier proteins. Pediatr Res 85: 405-411.

7. Hasegawa N, Yamada T, Mochizuki M (2020) Vitamin D3 supplementation ameliorates typical clinical symptoms in children with autism spectrum disorder in Japan: A case study. Int J Nurs Clin Pract 7: 318-311.

8. Tamblyn JA, Jenkinson C, Larner DP, Hewison M, Kilby MD, et al. (2018) Serum and urine vitamin $D$ metabolite analysis in early preeclampsia. Endocr Connect 7: 199-210.

9. Terada K, Matsushima Y, Matsusima K, Takata J, Karube $Y$, et al. (2018) The Kampo medicine Yokukansan (YKS) enhances nerve growth factor (NGF)induced neurite outgrowth in PC12 cells. Bosn J Basic Med Sci 18: 224-233.

10. Musiol IM, Stumpf WE, Bidmon HJ, Heiss C, Mayerhofer A, et al. (1992) Vitamin $D$ nuclear binding to neurons of the septal, substriatal and amygdaloid area in the Siberian hamster (Phodopussungorus) brain. Neuroscience 48: 841-848.

11. Bidmon HJ, Stumpf WE (1994) Distribution of the nuclear receptor for vitamin $\mathrm{D}$ in female and male zebra finches, Taeniopygia guttata. Cell Tissue Res 276: 333-345.

12. Roth DE, Gernand AD, Morris SK, Pezzack B, Islam MM, et al. (2018) Vitamin $\mathrm{D}$ supplementation in pregnancy and lactation to promote infant growth. N Engl J Med 379: 535-546.

13. Kalueff AV, Minasyan A, Keisala T, Kuuslahti M, Miettinen S, et al. (2006) The vitamin $D$ neuroendocrine system as a target for novel neurotropic drugs. CNS Neurol Disord Drug Targets 5: 363-371.

14. Chen J, Xin K, Wei J, Zhang K, Xiao H, et al. (2016) Lower maternal serum $25(\mathrm{OH}) \mathrm{D}$ in first trimester associated with higher autism risk in Chinese offspring. J Psychosom Res 89: 98-101.

15. WHO (2012) Guideline: Vitamin D supplementation in pregnant women, Geneva. World Health Organization. 